\title{
The Effect of Number of Storey's and Columns Dimensions on the Accuracy of Tributary Area Method
}

\author{
Imad Al-Qasem ${ }^{1}$, Mahmud Dwaikat ${ }^{1}$ and Mohanad Abdulwahid ${ }^{2}$ \\ ${ }^{l}$ Civil Engineering Department, An-Najah National University, Palestinian \\ ${ }^{2}$ Civil Engineering Department, Koya University, Kurdistan Region, Iraq
}

Received 25 November 2013; Accepted 19 March 2014

\begin{abstract}
In recent years, the utilization of computer techniques in engineering application has become an irreversible trend. This is achieved through using computer as the device for modeling, analysis, and design. The study mainly has focused on the accuracy of the tributary area method for estimation load, as compared to finite element method by SAP2000, considering the effect of building overall height (i.e. number of storey's) from 1 to 10 and column dimensions (i.e. stiffness) from $20 \times 20 \mathrm{~cm}$ to $70 \times 70 \mathrm{~cm}$. According to the analysis of the data obtained, we can see the error in the load computed by the tributary area approximation becomes relatively larger as the number of storey's increases, especially for the lateral load calculations, and the stiffness of the columns increases, the predictions using the tributary area method improves for both axial and lateral forces in the columns.
\end{abstract}

Keywords: Tributary area method, FEM analysis, Stiffness, Multi-storey building, Axial load

\section{Introduction}

In the conceptual design phase, structural engineers use tributary area method for load calculations that are needed for the initial proportioning of structural elements. A good use of the dimensions and proportions of the structural elements helps to increase the efficiency of the design process. Also, many engineers use the method as a simple cross-check for the validity of results obtained from numerical models (for example 3D finite element model of a building). Therefore, it is important to investigate the level of accuracy for the results produced by such simple method.

Many multi-storey building systems consist of a reinforced concrete slab supported on a reinforced concrete column. Loading on tall building differs from loading on low rise buildings in its accumulation into much larger structural forces, in the increased significance of wind loading, and in the greater importance of dynamic effects The collection of gravity loading over a large number of stories in a tall building can produce column loads of an order higher than those in low-rise building surface, but also with greater intensity at the greater heights and with a larger moment arm about the base than on a low-rise building ( Rajesh and Vinubhai 2013).

Tributary area method is one of methods which are being used to calculate the forces carried by columns in the buildings. The Tributary Area method is more suitable for masonry buildings and more widely used because of its suitability for hand calculation checks, and will also produce larger reactions in the walls and columns that terminate on a

\footnotetext{
*E-mail address: mohanad.yaseen@koyauniversity.org
}

transfer level (Paul 2006)

Many different researchers investigated the behavior of multi-storey building under gravity loads and lateral loads. (Kulkarni et al. 2013) investigated the behavior of reinforced concrete frames with 3 bay, 5 bay and 7 bay 9 storey structures subjected to gravity and seismic loads with varying inertia by using STAAD pro program.

The conventional axial force calculated on contributory area closely approximates the true load in column segment at higher levels for 3 bay 9 storey structures and the $2 / 3$ rd height of frame from bottom and larger at the topmost level for 5 bay 9 storey structures and the column segment at $1 / 3$ rd height of frame and it reduces for topmost level for 7 bay 9 storey structures.

(Ahmed and Khan 2013) studied the possibilities of performing nonlinear finite element analysis of RCC column under lateral load using ANSYS package software. Only non-linear stress-strain relations for concrete in compression have made it possible to reach ultimate load. It was also observed that with increasing the column size by 2 inches, the capacity increased by almost 80 percent.

(Ozgur and Lulec 2011) discussed the different analysis approaches for estimating the axial loads on columns and structural walls at tall buildings. The results show the tributary area method and finite element model of a single storey ignore the differential shortening of columns and walls, which resulted in an overestimation of column axial loads and an underestimation of wall axial loads.

As a common practice in the design process, and for economical purposes, the columns are categorized based on the load transferred to them. In a multi storey building, the columns in the first level are subjected to enormous loading, 
and such loading can cause axial deformations in these columns that are proportional to the load carried by the columns.

Naturally, such differential deformations can lead to load redistribution within the same floor level. Since the tributary area method does not account for the sectional properties of the columns, we would expect that the number of stories in the building will have a direct effect on the resulting forces in the columns.

Given the premise above, this paper presents a study on the effect of number of storey's on the validity of the tributary area method for load calculations. The paper aims are exploring the limits within which the method can be used comfortably in a design process.

For this purpose, a 3-D finite element model is created using a commercial package, and then the model is used to generate results for different cases. After that the results are compared to predictions made by the commonly used tributary area method. Discussion and conclusions are drawn from the analysis.

\section{Generic Finite Element Model}

Because the purpose of the analysis is to study the effect of the number of storey's on the axial load predicted by the tributary area method, different models are created. For all models, the assumptions made in the generic model are maintained, while other parameters, such as columns dimensions and number of storey's, vary for each model.

The model used in this study represents a generic multistorey building with the assumptions listed below. It is created using a commercial finite element program commonly used for structural analysis and design.

The program, SAP2000, is chosen because its interface is easy, flexible, systematic, and friendly user. Such characteristics make it a program of choice for a wide range of structural engineers.

The generic multi-storey building is modelled using SAP2000 as a three-dimensional frame with predefined input parameters, such as loading, members' dimensions, and materials. The plan view and 3D view of the generic model are shown in Fig. 1 and 2.

The assumptions made for the generic building are:

1. The floor is made of a flat plate slab with $40 \mathrm{~cm}$ thickness carried by nine columns, as shown in Fig. 1 and 2 .

2. The overall dimensions of the slabs are $12 \mathrm{~m} \times 12 \mathrm{~m}$ and divided into two spans in each direction, with each span equal $6 \mathrm{~m}$.

3. The height of the columns in the building equals $3 \mathrm{~m}$.

4. The footings of the columns are modelled as pin hinges.

5. All structural members are made from reinforced concrete.

\section{Cases for Analysis}

Two load cases are considered, namely, gravity and lateral loads. For each type, the generic model building (comprises of variable number of stories) is analyzed for different scenarios of columns used. The scenarios represent different column dimensions. For each target height of the generic building, columns dimensions of $20 \times 20 \mathrm{~cm}, 40 \times 40 \mathrm{~cm}$, and $70 \times 70 \mathrm{~cm}$ are used and generalized throughout the building. This variation of the columns dimensions is important in order to study the effect of the columns stiffness on the accuracy of the predictions from the tributary area method. More details on these load cases are provided below, followed by the results of the analysis and discussion.

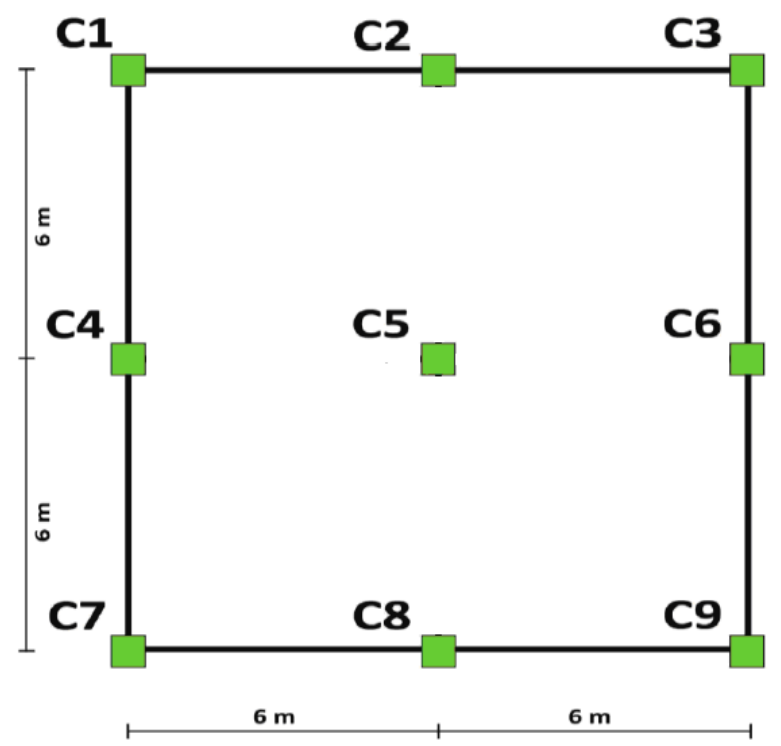

Fig. 1. 2D multi storey building model

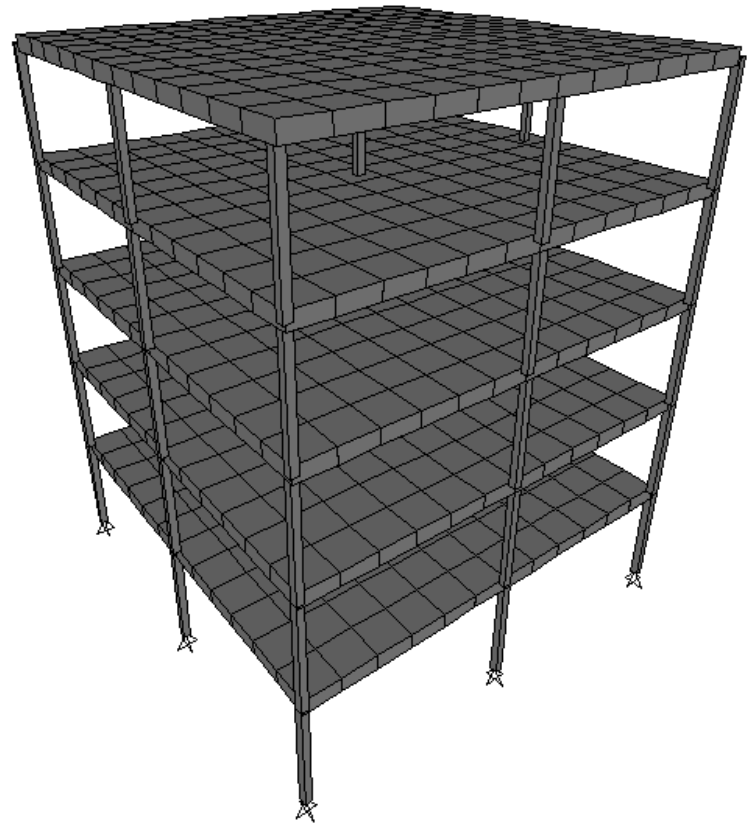

Fig. 2. A generic 3D model for the multi-storey building

\subsection{Analysis Under Gravity Loading}

In this case of analysis we analyze the multistory building under gravity load. We compare the results of axial load on the critical (ground) columns as obtained from the finite element model to that obtained by the tributary area method. In this analysis, we focus on the effect of varying the number of storey's on the axial load. For the purpose of comparison, the following "common" loads are assumed:

1. The own weight of slab $=0.4 * 2.5=1.0 \mathrm{t} / \mathrm{m}^{2}$

2. The supper imposed load $=0.3 \mathrm{t} / \mathrm{m}^{2}$

3. The live load $=0.25 \mathrm{t} / \mathrm{m}^{2}$ 
According to these assumptions, the ultimate load is calculated as:

$\left(\mathrm{w}_{\mathrm{u}}\right)=1.2 *(1+0.3)+1.6 * 0.25=2 \mathrm{t} / \mathrm{m}^{2}$

This load is considered to be uniformly distributed on the each floor. The columns under investigation are the corner, edge, and central columns.

\subsection{Analysis Under Horizontal Loading}

In this case we will analyze the multi-storey building model under horizontal load. Results of shear force which is carried by the ground columns from finite element model will be compared against the results obtained from tributary area method. In this case the following assumptions are used:

1. The horizontal uniform load $=0.25 \mathrm{t} / \mathrm{m}^{2}$.

2. The gravity load will be neglected, so as to show the effect of the horizontal load only.

3. The own weight of the slab will be neglected.

The tributary area method for lateral load calculations is conducted so that each column carries a lateral load proportionally to the ratio of its contributory area to the total area of the floor plan. Although such calculations are not accurate per se, it is still commonly used in the conceptual phase of the design process. It will be seen that such approach, on its simplicity, actually gives an indication of the lateral load in the columns. Similar to the case of gravity load, the columns under study are the corner, edge, and middle.

\section{Results and Discussion}

SAP2000 software and tributary area method have been used to analyze the generic multi-storey building model. Results are generated for the load cases mentioned above and considering different number of storey's and columns dimensions. The results and discussion are presented here in for different column positions.

\subsection{Comparison of Axial Load Estimation on Columns under Vertical Load}

Figures 3 show the axial load estimation in columns with different positions for different number of storey's and considering different dimensions of the columns. In the figure the load from tributary area method (TAM) is compared to loads from SAP2000 for different cases of columns dimensions $(20 \times 20 \mathrm{~cm}$ to $70 \times 70 \mathrm{~cm})$ and for different number of building heights (1 to 10 ).

As a general trend, we see that the deviation between the results from finite element and from tributary area becomes higher as the number of stories is increased. This can be attributed to the accumulation of errors in the tributary area due to its approximate nature. Also, it can be seen that the deviations become smaller as the dimensions of the columns become larger. In other words, the stiffer the columns become, the more accurate the tributary area method becomes.

Also, from the results in Fig. 3, it can be seen that:

1. The tributary area method (TAM), when compared to results from finite element, always produce conservative or slightly non-conservative predictions of the axial force in the central column as can be seen in Fig. 3(a). Such accuracy of predictions is generally acceptable for conceptual design phases where the accuracy is not the target. In general, the higher the stiffness of the central column, the better the predictions are.

2. If the dimensions of the corner column are $20 \mathrm{cx} 20 \mathrm{~cm}$ (i.e. low column stiffness), the axial load values from SAP2000 are closer to the predictions using tributary area method if the number of storey's is less than or equal five. If the number of stories is larger than 5 , the tributary area method underestimates the axial force, and thus produces non-conservative predictions as can be seen in Fig. 3(b). Increasing the dimensions of the columns (e.g. to $70 \mathrm{~cm} \times 70 \mathrm{~cm}$ ) leads to better (and conservative) predictions using tributary area method of the axial load in the corner column.

3. The axial load values on edge columns from tributary area method and from SAP2000 are almost similar regardless of the number of storeys and regardless of the columns stiffness. This is an interesting result as it simply indicates that the tributary area method is more reliable for application on edge columns, rather than on central columns.

This trend seems to be consistent with for all columns which are under gravity and lateral load cases. Interestingly enough, the tributary area method seem to provide the most accurate load predictions for the edge columns for both gravity and lateral load cases.

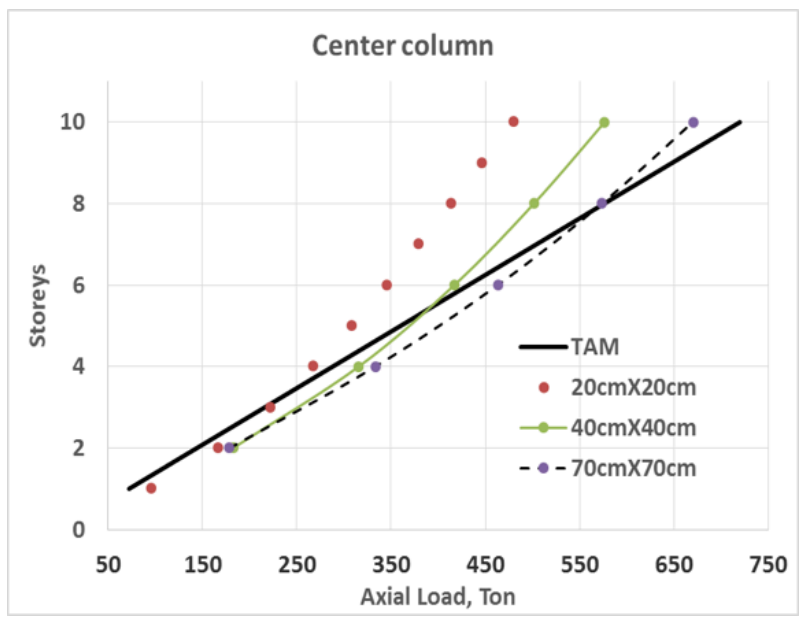

Corner column

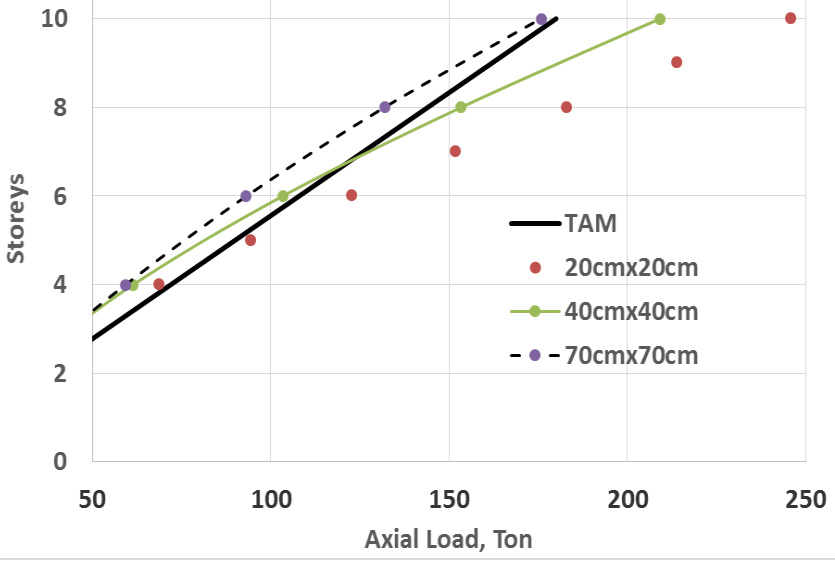




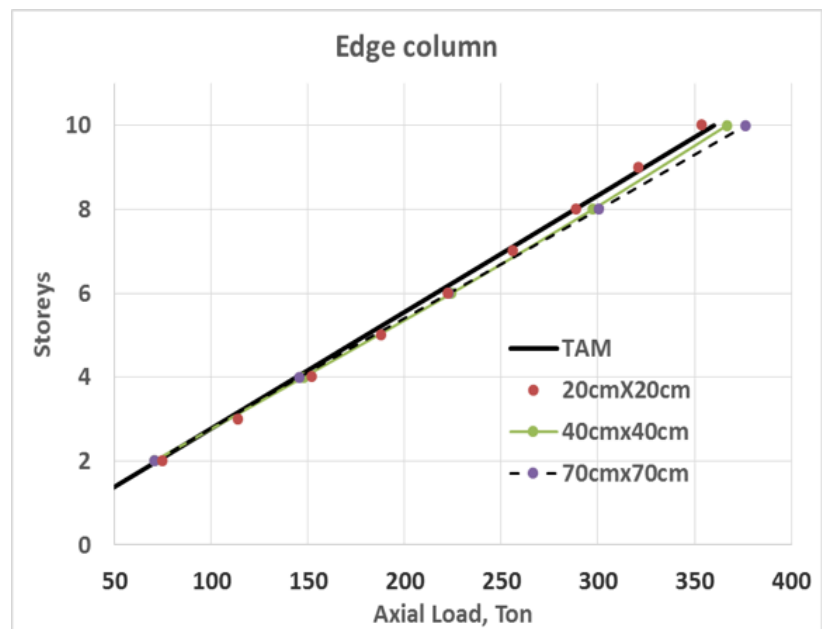

Fig. 3. Axial load in a) central, b) corner and c) edge columns with increasing number of storey's and considering variable columns dimensions (TAM $=$ results from tributary area method)

\subsection{Comparison of Lateral Load Estimation on Column Under Horizontal Load}

Figure 4 shows the lateral load estimation in columns with different positions and stiffness's and for different number of storeys. The lateral loads for columns were obtained from two analysis methods: tributary area method and SAP2000.

As a general trend of the results in Fig. 4, it can the dimensions (i.e. stiffness) of the columns increase, the results from finite element and from tributary area method become closer. The tributary area method always produces conservative results for the central and edge column. However for the corner column the method seems to produce non-conservative predictions.

Specifically, the following results can be drawn from this case of analysis:

1. The axial load values on the corner columns by SAP2000 are greater than them by tributary area method regardless of number of storey's or column stiffness's.

2. The tributary area method provides reasonably good prediction of the lateral load in edge column when compared to finite element, regardless of the number of storey's or column dimensions.

3. The axial load values on the central columns by tributary area method are more than the values estimation by SAP2000 for all number of stories and for different column dimensions.
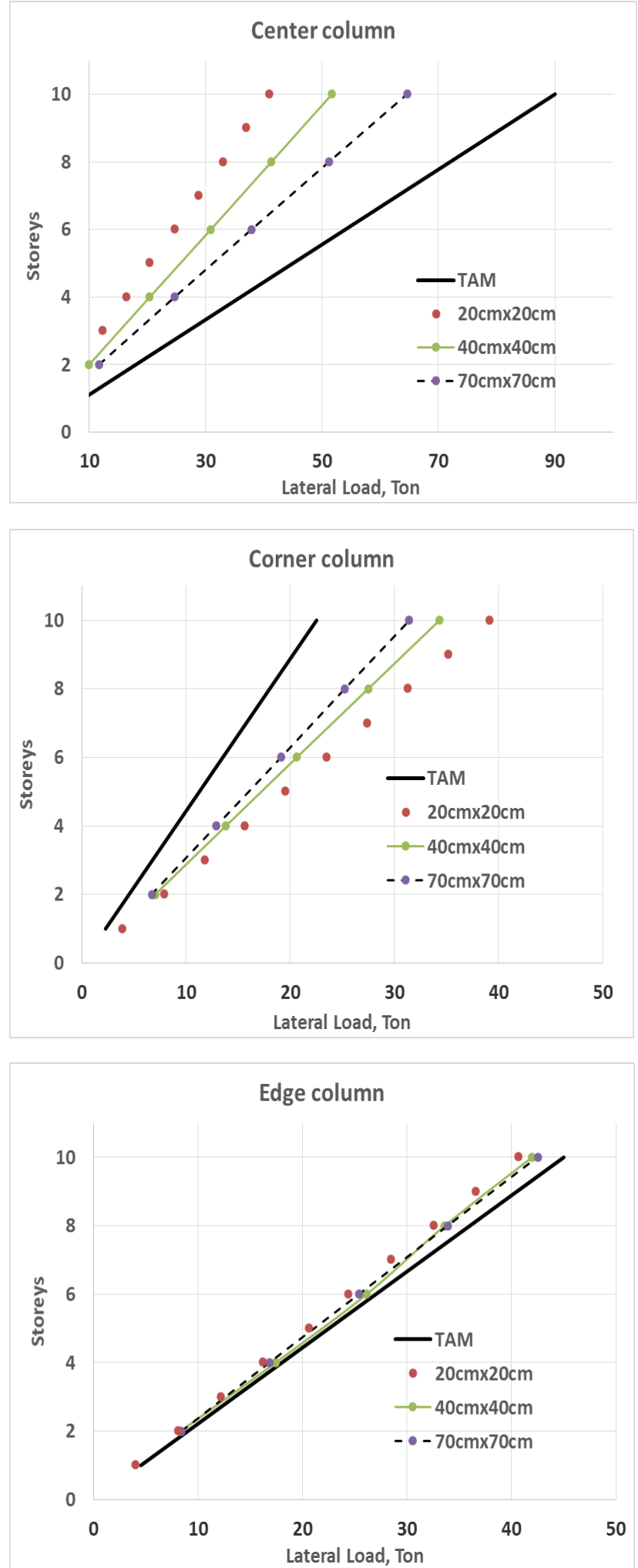

Fig. 4. Lateral load in a) central, b) corner and c) edge columns with increasing number of storey's and considering variable columns dimensions $(\mathrm{TAM}=$ results from tributary area method)

\section{Conclusions}

In this paper, the tributary area method, as a tool commonly used in conceptual design phases, is compared to finite element method. The study mainly has focused on the accuracy of the tributary area method, as compared to finite element method, considering the effect of building overall 
height (i.e. number of stories) and column dimensions (i.e.stiffnesses). The following general conclusions could be drawn from the study:

- The tributary area method provides a simple tool forreasonably predicting the axial force in columns. In case of lateral load predictions, the method might produce nonconservative estimates of lateral load in corner columns.
In general, as the stiffness of the columns increases, the predictions using the tributary area method improves for both axial and lateral forces in the columns.

In general, the error in the load computed by the tributary area approximation becomes relatively larger as the number of storey's increases, especially for the lateral load calculations.

\section{References}

[1] Rajesh and Prajapati. (2013). "Effect of Different Position of Shear Wall on Deflection in High Rise Building" International Journal of Advances in Engineering \& Technology, 6 (4), 1848-1854.

[2] Paul. (2006). "Transfer floor design strategy using R/C BUILDING software". INDUCTA Engineering, pp 2-3

[3] Kulkarni et al. (2013)"Analysis of Multi-storey Building Frames Subjected to Gravity and Seismic Loads with Varying Inertia", International Journal of Engineering and Innovative Technology (IJEIT), 2(10), 132-138
[4] Ahmed and Khan. (2013) "Finite Element Analysis of Reinforced Concrete Column Under Lateral Load", International Journal of Engineering Research and Applications, 3(4), 228-231.

[5] Ozgur and Lulec.(2011) " A comparative study on different analysis approaches for estimating the axial loads on columns and structural walls at tall buildings", The Structural Design of Tall and Special Buildings, 22(6),485-499 